\title{
The impact on life cycle carbon footprint of converting from disposable to reusable sharps containers in a large US hospital geographically distant from manufacturing and processing facilities
}

\author{
Brett McPherson ${ }^{1}$, Mihray Sharip ${ }^{2}$, Terry Grimmond ${ }^{\text {Corresp. } 3}$ \\ 1 Director, Environmental Health, Loma Linda University Health, San Bernardino, CA, United States \\ 2 Environmental Health Specialist, Loma Linda University Health, San Bernardino, CA, United States \\ 3 Director, Grimmond and Associates, Microbiology Consultancy, Hamilton, New Zealand \\ Corresponding Author: Terry Grimmond \\ Email address: terry@terrygrimmond.com
}

Background. Sustainable purchasing can reduce greenhouse gas (GHG) emissions at healthcare facilities (HCF). A previous study found that converting from disposable to reusable sharps containers (DSC, RSC) reduced sharps waste stream GHG by $84 \%$ but found transport distances impacted significantly on GHG outcomes and recommended further studies where transport distances are large. This case-study examines the impact on GHG of nation-wide transport distances when a large US health system converted from DSC to RSC.

Methods. The study's scope was to examine life cycle GHG emissions during 12 months of facility-wide use of DSC and RSC at Loma Linda University Health (LLUH). The facility is an 1100-bed US, 5-hospital system where: the source of polymer was distant from the RSC manufacturing plant; both manufacturing plants were over 3,000 km from the HCF; and the RSC processing plant was considerably further from the HCF than was the DSC disposal plant. Using a "cradle to grave" life cycle GHG tool we calculated the annual GHG emissions of $\mathrm{CO}_{2}, \mathrm{CH}_{4}$ and $\mathrm{N}_{2} \mathrm{O}$ expressed in metric tonnes of carbon dioxide equivalents $\left(\mathrm{MTCO}_{2} \mathrm{eq}\right)$ for each container system. Primary energy input data was used wherever possible and regionspecific energy-impact conversions were used to calculate GHG of each unit process over a 12-month period. The scope included Manufacture, Transport, Washing, and Treatment $\&$ disposal. GHG emissions from all unit process within these four life cycle stages were summed to estimate each containersystem's carbon footprint. Emission totals were workload-normalized and analysed using $\mathrm{CHI}^{2}$ test with $P \leq 0.05$ and rate ratios at $95 \% \mathrm{CL}$.

Results. Converting to RSC, LLUH reduced its annual GHG by 162.4 MTCO2eq $(-65.3 \% ; p<0.001 ;$ RR 2.27-3.71), and annually eliminated 50.2 tonnes of plastic DSC and 8.1 tonnes of cardboard from the sharps waste stream. Of the plastic eliminated, 31.8 tonnes were diverted from landfill and 18.4 from incineration.

Discussion. Unlike GHG reduction strategies dependent on changes in staff behavior (waste segregation, recycling, turning off lights, car-pooling, etc), purchasing strategies can enable immediate, sustainable and institution-wide GHG reductions to be achieved. This study confirmed that large transport distances between polymer manufacturer, container manufacturer, user and processing facilities, can significantly impact the carbon footprint of sharps containment systems. However, even with large transport distances, we found that a large university health system significantly reduced the carbon footprint of their sharps waste stream by converting from DSC to RSC. 
1 The impact on life cycle carbon footprint of converting from disposable to reusable sharps

2 containers in a large US hospital geographically distant from manufacturing and

3 processing facilities

5 Brett McPherson ${ }^{1}$ BSN, Mihray Sharip ${ }^{2}$ MS, REHS, CHMM, Terry Grimmond ${ }^{3}$ FASM,

6 BAgrSc, GrDpAdEd\&Tr

$7 \quad{ }^{1}$ Director Environmental Health, Loma Linda University Health, Loma Linda, CA, USA

8 2Environmental Health Specialist, Loma Linda University Health, Loma Linda, CA, USA

9 32Director, Grimmond and Associates, Microbiology Consultants, Hamilton, New Zealand

11 Corresponding author: Terry Grimmond, 930 River Rd Queenwood, Hamilton New Zealand 3210.

12 Em: terry@terrygrimmond.com Ph: +64 274365140

14 Abstract

15 Background. Sustainable purchasing can reduce greenhouse gas (GHG) emissions at healthcare

16 facilities (HCF). A previous study found that converting from disposable to reusable sharps

17 containers (DSC, RSC) reduced sharps waste stream GHG by $84 \%$ but found transport distances

18 impacted significantly on GHG outcomes and recommended further studies where transport

19 distances are large. This case-study examines the impact on GHG of nation-wide transport

20 distances when a large US health system converted from DSC to RSC.

21 Methods. The study's scope was to examine life cycle GHG emissions during 12 months of

22 facility-wide use of DSC and RSC at Loma Linda University Health (LLUH). The facility is an

23 1100-bed US, 5-hospital system where: the source of polymer was distant from the RSC 
24 manufacturing plant; both manufacturing plants were over 3,000 km from the HCF; and the RSC

25 processing plant was considerably further from the HCF than was the DSC disposal plant. Using

26 a "cradle to grave" life cycle GHG tool we calculated the annual GHG emissions of $\mathrm{CO}_{2}, \mathrm{CH}_{4}$

27 and $\mathrm{N}_{2} \mathrm{O}$ expressed in metric tonnes of carbon dioxide equivalents $\left(\mathrm{MTCO}_{2} \mathrm{eq}\right)$ for each

28 container system. Primary energy input data was used wherever possible and region-specific

29 energy-impact conversions were used to calculate GHG of each unit process over a 12-month

30 period. The scope included Manufacture, Transport, Washing, and Treatment \& disposal. GHG

31 emissions from all unit process within these four life cycle stages were summed

32 to estimate each container-system's carbon footprint. Emission totals were workload-normalized

33 and analysed using $\mathrm{CHI}^{2}$ test with $P \leq 0.05$ and rate ratios at $95 \% \mathrm{CL}$.

34 Results. Converting to RSC, LLUH reduced its annual GHG by 162.4 MTCO2eq (-65.3\%; $\mathrm{p}<$

35 0.001; RR 2.27-3.71), and annually eliminated 50.2 tonnes of plastic DSC and 8.1 tonnes of

36 cardboard from the sharps waste stream. Of the plastic eliminated, 31.8 tonnes were diverted

37 from landfill and 18.4 from incineration.

38 Discussion. Unlike GHG reduction strategies dependent on changes in staff behaviour (waste

39 segregation, recycling, turning off lights, car-pooling, etc), purchasing strategies can enable

40 immediate, sustainable and institution-wide GHG reductions to be achieved. This study

41 confirmed that large transport distances between polymer-manufacturer, container-manufacturer,

42 user and processing facilities, can significantly impact the carbon footprint of sharps containment

43 systems. However, even with large transport distances, we found that a large university health

44 system significantly reduced the carbon footprint of their sharps waste stream by converting

45 from DSC to RSC. 


\section{INTRODUCTION}

48 Healthcare activities account for 5.4\% of greenhouse gas (GHG) emissions in the U.K. (NHS, 49 2016; DBEIS, 2017) and 9.8\% in U.S. (Eckelman and Sherman, 2016) and, in hospitals, more

50 than half of GHG emissions are derived from supply chain goods and services (NHS, 2017).

51 Many hospitals are adopting green purchasing strategies to reduce their GHG (Chung \& Meltzer, 52 2009; NHS, 2017) - a position supported by the Alliance of Nurses for Health Environments

53 (ANHE, 2017). Replacing disposable products with reusables is such an example (WHO-HCWH

54 2009, Unger et al., 2016; Karrlson and Ohman, 2005) and, as clinical waste containers are in the

55 top 20 contributors to the supply chain carbon footprint (NHS, 2017), replacing disposable

56 sharps containers (DSC) with reusable sharps containers (RSC) is recommended (PGH, 2013).

57 One life cycle carbon footprint study found that converting from DSC to RSC achieved a

58 significant reduction in GHG however the authors' sensitivity analysis found transport distances

59 could significantly affect results and, given the hospital was close to where both containers were

60 manufactured, recommended that scenarios with large transport distances be investigated

61 (Grimmond and Reiner, 2012). Our case-study compares the annual impact on life cycle carbon

62 footprint of converting from DSC to RSC at a large U.S. teaching hospital system sited at nation63 wide distances from manufacturing plants.

MAterials ANd Methods

\section{Study Overview}

67 The scope of the study was to examine the life cycle carbon footprint of DSC and RSC over a

68 12-month period of facility-wide usage at a hospital geographically distant from manufacturing 
69 and processing plants, and include all unit processes in Manufacture, Transport, Washing, and

70 Treatment \& disposal stages.

71 Using established principles for assessment of the life cycle GHG emissions of goods and

72 services (British Standards Institute, 2011) we utilised a cradle-to-grave life cycle inventory

73 (LCI) and a product-system GHG assessment tool developed specifically for sharps containers

74 and containing some 750 data cells (Grimmond and Reiner, 2012). In a before-after intervention

75 study using a calculation model, we compared the annual GHG emissions for facility-wide usage

76 of DSC and RSC at Loma Linda University Health (LLUH). The facility is an 1100 bed

77 university healthcare system with 5 general acute care hospitals and an expansive outpatient

78 clinic system in Loma Linda, California. The GHG included were $\mathrm{CO}_{2}, \mathrm{CH}_{4}$ and $\mathrm{N}_{2} \mathrm{O}$ as these

79 represent more than $99.5 \%$ of $\mathrm{CO}_{2}$ eq generated during the major life cycle stages of sharps

80 containers (American Chemistry Council, 2010, USEPA 2016). Greenhouse gases, other than

$81 \mathrm{CO} 2$, were converted to their $\mathrm{CO} 2$ eq on the basis of their per unit radiative forcing using 100-

82 year global warming potentials defined by the Intergovernmental Panel on Climate Change

83 (British Standards Institute, 2011). The annual GHG emissions for each container's life cycle

84 were expressed in metric tonnes of carbon dioxide equivalents $\left(\mathrm{MTCO}_{2} \mathrm{eq}\right)$. All GHG data

85 sources used in the study provided GHG outcomes as MTCO2eq. Review Board approval by

86 LLUH was waived as no patients, patient data or patient specimens were involved.

87 The LCI itemised all energy-using processes required by each containment system's life-cycle as

88 implemented at LLUH. Scope 1, 2 and 3 processes were included in both study years. Unit process

89 GHG were collated into the following life-cycle stages: manufacture (of polymer and containers);

90 transport; washing (RSC); and treatment \& disposal. We assessed GHG emissions from all

91 energy used in these processes (vehicle fuel, gas, electricity, water supply and treatment) and in 
92 the manufacture and life cycle of ancillary products (pallets, transport cabinets, cardboard boxes,

93 wash products). The boundary of the system studied, together with inputs, outputs and

94 exclusions, are shown in figure 1.

\section{Data Sources}

96 The following data sources were used in calculating GHG: DSC and RSC resin manufacture

97 (American Chemistry Council, 2010); primary energy input data for DSC and RSC container

98 manufacture (Clarion 2011) and RSC washing (Daniels, 2017); industry-specific data for DSC

99 autoclaving (Daniels, 2012); RSC and DSC transport (DEFRA, 2015); eGRID values for

100 California, Michigan and Illinois power generation (USEPA eGRID 2016); National data for

101 energy inputs for US water supply and treatment (Chini and Stillwell, 2018); Industry data for

102 manufacture of wash products (Nielsen et al, 2013; Shahmohammadi et al, 2017); Industry data

103 for manufacture of cardboard (NCASI 2017), representative data for manufacture of transporters

104 (USDOE, 2010); Industry-specific data for pallet life cycle GHG (DEFRA, 2010): and US

105 national values for incineration of DSC (USEPA WARM, 2018). The same database and values

106 were applied to the relevant unit processes in DSC and RSC systems. Emissions for RSC

107 manufacturing were calculated using a worst-case scenario based on the actual age of the

108 manufacturer's oldest, most frequently used RSC still in service nationally. Although it is

109 theoretically possible for RSC to be recertified for a further period when they reach their

110 certified reuse expiration, for this study their "end-of-life" was conservatively taken to be the

111 number of years under the above worst-case scenario. The GHG associated with manufacture of

112 ancillary reusables (transport-cabinets and pallets) were calculated on a per trip basis using their

113 expected life span. Data on container size, model number, number used, and total Adjusted

114 Patient Days (APD) (workload indicator) were obtained from LLUH. Total polymer required for 
115 manufacture of DSC and RSC was determined by weighing an example of each model of

116 container and multiplying by the number of containers. The conversion-transition period (2

117 years) was excluded to avoid system overlap. Emission totals for each system's annual use were

118 workload-normalized by dividing its life cycle MTCO2eq by the APD for that year. The two

119 ratios were then analyzed using WinPepi v11.65 (WinPepi, 2016). A Yates-corrected $\chi 2$ test was

120 used for the analysis of proportions. Statistical significance was set at $P \leq .05$ and rate ratios

121 calculated using $95 \%$ confidence intervals.

122 System Function, Boundary, Allocation and Classification

123 The system function provided by the alternative products (DSC, RSC) was the supply of sharps

124 containers for the disposal of sharps waste (biological, chemotherapeutic, pharmaceutical) within

125 LLUH. The functional unit was the supply of each system for a one-year period. Sharps waste is a

126 sub-category of medical waste and comprises items capable of penetrating human skin (e.g. needles,

127 scalpels) which may have the potential to transmit infectious disease or pose a physical or chemical

128 hazard. Because of these hazards, at disposal, all sharps must be safely contained in either DSC or

129 RSC and transported to a treatment facility. With DSC the container is used once and the intact

130 container and contents are subjected to treatment (commonly autoclaving, or incineration) prior to

131 landfill. With RSC, the container is automatedly decanted of its contents (which are treated and

132 disposed), and the reusable container is robotically cleaned and decontaminated, and reused a defined

133 number of times. The boundary of the system studied (Figure 1) included the energy required for the

134 following unit processes: raw material extraction; polymer manufacture and transport; container

135 manufacture and transport; transport of full containers to treatment facility; RSC processing-energy

136 (including water supply, water treatment, and wash products); treatment of DSC; transport of treated

137 DSC to landfill; and energy required for electricity generation and supply. Transport fuel processes 
138 were calculated from well to wheel. Excluded from the system boundary were treatment of container

139 contents (identical in both DSC and RSC), infrastructure and assets, and any inputs and outputs that

140 comprised less than 1\% of mass or energy (British Standards Institute, 2011), or were not relevant

141 to carbon footprint.

142 The production of polymer from oil or gas is a multi-function process and allocation of emissions

143 and resource use was performed on a mass basis, as was transport, autoclaving and pallet

144 manufacture. The injection-molding of DSC/RSC and the processing (cleaning and decontamination)

145 of RSC are single-function processes and no allocation to co-products was necessary. Incineration of

146 chemotherapeutic and pharmaceutical DSC was carried out in waste to energy incinerators that co-

147 produce electricity and the avoided utility emissions were subtracted to give net GHG emissions per

148 ton of specific polymer incinerated (USEPA WARM, 2018). In cardboard production (1.7\% of total

149 DSC life-cycle GHG) allocation was averaged using cut-off and number-of-uses methods where

150 appropriate (NCASI 2017). Regional emissions reported in eGrid represent electricity generation

151 only - any emissions used for purposes other than making electricity were excluded from the

152 adjusted emissions (USEPA eGRID 2016).

153 Global warming was the impact assessment category to which all inventory data was classified as it

154 is well-known and commonly used and understood by healthcare facilities. A table listing the raw

155 data for all unit processes including flow, units, conversion factors, total GHG, data sources and data156 representativeness, accompanies this publication.

\section{RESULTS}

159 DSC were manufactured in Crystal Lakes IL from US-sourced polypropylene polymer, nested in 160 cardboard containers, transported $3,200 \mathrm{~km}$ to the hospital on wooden pallets, and autoclaved and 
161 landfilled without shredding at Vernon CA, 130km from the hospital. The RSC were manufactured

162 in Greenville MI from polymer sourced in Korea, transported 3,500km in reusable, proprietary

163 transporter cabinets to LLUH, and decanted and processed at Fresno CA, 440km from the hospital.

164 A summary of results is presented in the Table.

165 To service LLUH in the baseline year, 48,460 DSC were manufactured from 50.6 tonnes of polymer

166 and required 8.2 tonnes of corrugated cardboard packaging for transport (see Table). The DSC used

167 did not contain recycled polymer. In California, biological sharps are treated by non-incineration

168 technologies (e.g. autoclave) then landfilled; chemotherapeutic and pharmaceutical sharps must be

169 incinerated (and ash landfilled) - this requires transport interstate as there are no licensed incinerators

170 for such wastes in California. With DSC, this resulted in 31.8 tonnes of plastic DSC being landfilled

171 and 18.8 tonnes of DSC being transported interstate for incineration (Table 1).

172 In the RSC year, 2,779 RSC were manufactured from 9.6 tonnes of acrylonitrile butadiene styrene

173 (ABS) polymer, and 0.4 tonnes of cardboard were used for packaging of 412 chemo DSC that were

174 continued to be used (no cardboard is used for RSC packaging). During the RSC study year,

175 approximately $60 \mathrm{RSC}$ required repair with $30 \mathrm{~kg}$ parts being recycled (80\%) or reused (20\%) (nil to

176 landfill), and, with recycling credit, an equivalent of 3.7 RSC were manufactured as replacement

177 containers (2,783 RSC total for year). In the RSC study-year, the manufacture, treatment and

178 disposal of 412 chemotherapy DSC were included. The RSC in this study, certified for 500 uses,

179 were reused an average of 12.0 times/year at LLUH, giving a theoretical "end-of-life" lifespan of

18041.7 years. However a “worst-case" lifespan scenario was adopted based on manufacturer's data on

181 the number of reuses of the most frequently used RSC still in service in the US (each individual RSC

182 is barcoded and its uses monitored). The manufacturer stated their oldest and most frequently used

183 RSC still in service in the US was 19 years old and had been used 360 times, thus giving a "worst- 
184 case" lifespan of 26.4 years for this container. Manufacturing GHG for RSC (calculated by dividing

185 total manufacturing GHG by life expectancy) was $1135 \mathrm{~kg} \mathrm{CO} 2 \mathrm{eq}$ for a lifespan of 41.7 years $(1.3 \%$

186 of total RSC life-cycle GHG) and $1795 \mathrm{kgCO} 2 \mathrm{eq}$ for a worst-case lifespan of 26.4 years $(2.1 \%$ of

187 total RSC life-cycle GHG). The shorter, worst-case lifespan was used in this study. Total GHG

188 emissions and GHG differences between DSC and RSC life cycle stages are shown in Figure 2.

189 Adjusting for the $0.3 \%$ APD workload increase in the year of RSC use, sharps management GHG

190 using DSC was 248.6 MTCO2eq, and with RSC use, decreased to 86.20 MTCO2eq, a 162.4

191 MTCO2eq reduction in carbon footprint (65.3\%, p<0.001, RR 2.27-3.71) (See Table and Figure 2).

192 In addition to the GHG reduction with RSC, LLUH annually eliminated 50.2 tonnes of plastic

193 DSC and 8.1 tonnes of cardboard from the sharps waste stream. Of the plastic eliminated, 31.8

194 tonnes were diverted from landfill and 18.4 from incineration.

196 DisCUSSION

197 Background and impact of distances

198 Commercial RSC, first used in US and Australia in 1986, now represent approximately 50\%

199 and $75 \%$ respectively of the sharps containers used in these countries, and since 1999 have been

200 increasingly used in Canada, UK, Ireland, New Zealand, South Africa and South America.

201 Generally, RSC are reused many times per year and, with rugged construction and effective 202 inspection and repair, may last several decades. Prior to marketing in the U.S., RSC and DSC

203 are required by the U.S. Food and Drug Administration (FDA) to pass identical performance 204 tests and design requirements as stipulated in sharps container standards (FDA, 1993).

205 However, prior to this testing, FDA require RSC to undergo "lifespan simulation" and suggest 
206

207

208 (i) The containers be filled \& processed for the number of lifespan uses stated by the manufacturer (e.g. 500 times); then,

(ii) the same containers be subjected to a transport vibration test, e.g. US Department of Transport Packaging Vibration Standard (USDOT, 2001), and then,

(iii) the same containers must pass the tests and performance criteria of a Sharps Container Standard.

Likewise, the Canadian sharps container standard does not distinguish between DSC and RSC in its performance test requirements and requires lifespan simulation of RSC prior to testing (CSA, 2014).

One reason healthcare facilities adopt RSC is for environmental sustainability (PGH, 2013) but quantitative studies confirming this fact are rare (Unger et al 2016, Karrlson \& Ohman 2005).

A government study in the UK confirmed medical waste containers are among the top 20 items that account for more than $70 \%$ of the supply chain footprint and, to reduce the footprint, recommended: manufacturers report footprints of their products; reductions in quantity purchased; and sourcing of low carbon alternatives; (NHS, 2017). Our study found that converting from DSC to RSC significantly reduced the carbon footprint, and eliminated 50.2 tonnes of plastic and 8.1 tonnes of cardboard from the sharps waste stream.

Although the same RSC may be reused several hundred times, energy is required for their robotic washing between uses and, being heavier than DSC, their greater weight means more energy is required per unit for transport and manufacture. Ali et al noted that GHG increase considerably when medical waste is transported longer distances (Ali et al, 2017). A previous life cycle study found that when container-manufacturing plants and RSC processing plant are close to the healthcare facility (HCF), the conversion to RSC resulted in an $83.5 \%$ reduction in GHG, 
229 and transport contributed 25.8\% to the RSC life-cycle GHG (Grimmond and Reiner 2012). In

230 our study, the HCF was 3,500km from the RSC manufacturing plant, and, more importantly

231 (because of daily delivery), the RSC processing plant was $440 \mathrm{~km}$ from the HCF. This resulted in

232 transport GHG accounting for $90.6 \%$ of the RSC life-cycle GHG (see Figure 2). However,

233 notwithstanding that these longer distances lessened the GHG differential between DSC and

234 RSC, the conversion to RSC significantly reduced total sharps waste management GHG by

$23565.3 \%$. The reduced number of container exchanges with RSC (with associated labor reduction)

236 was also noteworthy (Table 1). The reduction in sharps management GHG with RSC use, while

237 only a small component of the total supply chain emissions at LLUH, has been a positive step in

238 the institution's sustainability strategies. Unlike GHG reduction strategies dependent on changes in

239 staff behaviour (waste segregation, turning off lights, car-pooling, etc), our study confirms that

240 purchasing strategies can enable immediate, sustainable and institution-wide GHG reductions to be

241 achieved.

242

243 Impact on GHG over 10 years

244 The impact of repeated DSC manufacture and one-off RSC manufacture is best illustrated over

245 multiple years. In the LLUH scenario over a 10-year period, 484,600 DSC would need be

246 manufactured compared to 2783 RSC (and 4,120 chemo DSC), and would divert 502 tonnes of

247 plastic from landfill or incineration.

\section{Sensitivity analysis}

250 Manufacturing (of polymer and containers) gave the largest differential between the two systems

251 (See Figure 2) and is predominantly a function of the energy required for the higher total 
252 polymer weight needed to be annually manufactured and molded for DSC. Although more DSC

253 required transportation from the distant manufacturing plant, the daily transport of RSC from the

254 distant processing plant resulted in a similar transportation GHG for both systems over the year

255 (see Figure 2). The sensitivity analysis revealed that variations in RSC lifespan contributed little

256 to the GHG result - reducing RSC lifespan from a theoretical 41.7 years to 26.4 years (used in

257 this study) or 15 years, reduced the DSC:RSC GHG difference by only $0.4 \%$, and $1.3 \%$

258 respectively.

259 Electricity "cleanliness" across US grids (e.g. wind, coal, hydro) is a key variable in comparative

260 GHG analyses (Unger et al., 2016) and the sensitivity analysis in our study showed that differing US

261 electricity sources can alter processing and manufacturing GHG by $82 \%$ which, when extrapolated to

262 the total life-cycle, can alter DSC GHG by $23 \%$ and RSC GHG by $10 \%$. Optimization of

263 reprocessing of medical products is recommended to lower GHG (Unger et al., 2016) however, in

264 this scenario, RSC reprocessing accounted for only 5.6\% of total RSC life-cycle GHG. Our analysis

265 confirmed findings of other studies (Grimmond and Reiner, 2012, Unger et al., 2016), that material

266 reclamation could reduce DSC life-cycle GHG if reclaimed plastic is used to offset virgin polymer

267 use.

268

269 Other impacts of RSC

270 The focus of this study was carbon footprint however cost reduction (Grimmond and Reiner,

271 2012) and sharps injury reduction (Grimmond et al., 2010) have also been associated with RSC

272 use and these factors, together with sustainability and mandatory frontline staff evaluation, were

273 considered prior to adoption of the RSC system by LLUH. In terms of environmental impacts,

274 we considered only one, global warming, however other impact categories such as ozone 
275 depletion, ecotoxicity, acidification, particulate matter, eutrophication, and human toxicity, may

276 enable additional conclusions to be drawn (Eckelman and Sherman, 2016).

277

278 Study Limitations and strengths

279 One limitation of the study was the assumption made in the location of manufacture of polymer

280 for the DSC. To limit the impact of this assumption, the location was conservatively assumed to

281 be a United States polymer-supplier close to the point of manufacture of the DSC. A second

282 limitation was the use of the UK DEFRA database for transport energy inputs. This was

283 necessary as no relevant United States database using tonne.km was available; however, all

284 databases were applied equally to DSC and RSC systems. Study strengths were in the

285 availability of 12 months of detailed usage data for both systems; the large transport distances

286 compared to previous studies; the use of a conservative RSC lifespan; and the primary and

287 region-specific availability of energy input data for unit processes in both systems.

288

289 CONCLUSIONS

290 - Large RSC transport distances lessen the differential between DSC and RSC GHG,

291 however, RSC still achieved significant GHG reductions over DSC.

292 - Transport \& electricity cleanliness are key factors in GHG of sharps waste management.

293 - RSC lifespan has minimal effect on carbon footprint comparisons of container-types.

294 - Purchasing decisions can significantly contribute to HCF GHG-reduction strategies.

295 - Institution-wide adoption of RSC can reduce GHG with minimal staff behavior-change.

296

297 REFERENCES 
298 Ali SM, Weng W, Chaudhry N. Application of life cycle assessment for hospital solid waste

299 management: A case study. Journal of the Air \& Waste Management Association, 66:10, 1012-

300 1018, DOI: 10.1080/10962247.2016.1196263.

301 American Chemistry Council, 2010. Cradle-to-gate life cycle inventory of nine plastics resins

302 and four polyurethane precursors. Prepared by Franklin Associates for the Plastic Division of the

303 American Chemistry Councilhttps://plastics.americanchemistry.com/Life cycle-Inventory-of-9-

304 Plastics-Resins-and-4-Polyurethane-Precursors-Rpt-Only/ (accessed May 21, 2018).

305 ANHE, 2017. Climate Change, Health, and Nursing: A Call to Action, 2017. Alliance of Nurses

306 for Health Environments. https://envirn.org/climate-change-health-and-nursing/ (accessed May

307 21, 2018).

308 British Standards Institute, 2011. BSI PAS 2050:2011. Specification for the assessment of the

309 life cycle greenhouse gas emissions of goods and services. British Standards Institution, London,

310 United Kingdom.

311 CSA, 2014. Canada Standards Association CSA Z316.6-14: Evaluation of single-use and

312 reusable medical sharps containers for Biohazardous and cytotoxic waste. Canadian Standards

313 Association, Mississauga ON L4W 5N6 Canada.

314 Chini C and Stillwell A. 2018. The state of U.S. Urban Water: Data and the Energy-Water

315 Nexus. Water Resources Research, 54, 1796-1811.

316 https://agupubs.onlinelibrary.wiley.com/doi/epdf/10.1002/2017WR022265 (accessed May 21, 317 2018).

318 Chung JW and Meltzer DO, 2009. Estimate of the Carbon Footprint of the US Health Care

319 Sector. JAMA, 302(18),1970-1972. doi:10.1001/jama.2009.1610. 
320 Clarion, 2014. Energy requirements for the injection molding of sharps containers manufactured

321 from polypropylene and acrylonitrile butadiene styrene polymers. Clarion Technologies, Inc.

322 Greenville, M, USA.

323 Daniels, 2012. Energy data required for the autoclave-processing of medical waste. Daniels

324 Health, Dandenong, Vic, Australia.

325 Daniels, 2017. Energy data required for the processing of reusable sharps containers. Daniels

326 Health, Dandenong, Vic, Australia.

327 DBEIS, 2017. Final UK greenhouse gas emissions national statistics 1990-2015, Table 3

328 Estimated emissions of Greenhouse Gases by source category, UK 1990-2015. 7 February 2017.

329 Department for Business, Energy \& Industrial Strategy, UK.

330 https://www.gov.uk/government/uploads/system/uploads/attachment_data/file/589604/2015 Fin

331 al_Emissions_data tables.xlsx (accessed Oct 14, 2018).

332 DEFRA, 2015. Department for Environment, Food \& Rural Affairs - GOV.UK. GHG

333 Conversion Factors for company Reporting.

334 https://www.gov.uk/government/publications/greenhouse-gas-reporting-conversion-factors-2015

335 (accessed May 21, 2018)

336 DEFRA, 2010. Guidance on measuring and reporting Greenhouse Gas (GHG) emissions from

337 freight transport operations, 2010. DEFRA and Industry Consortium.

338 https:/www.gov.uk/government/uploads/system/uploads/attachment data/file/218574/ghg-

339 freight-guide.pdf (accessed May 21, 2018).

340 Eckelman MJ, Sherman J (2016). Environmental Impacts of the U.S. Health Care System and

341 Effects on Public Health. PLoS ONE 11(6): e0157014. doi:10.1371/journal.pone.0157014. 
342 https://journals.plos.org/plosone/article?id=10.1371/journal.pone.0157014. Accessed Oct 14,

3432018.

344 FDA, 1993. Guidance on the Content and Format of Premarket (510(k)) Submissions for Sharps

345 Containers, Oct 1993. Infection Control Devices Branch, Office of Device Evaluation, U.S. Food

346 and Drug Administration, Silver Spring, MD USA.

347 https://www.fda.gov/downloads/medicaldevices/deviceregulationandguidance/guidancedocumen

348 ts/ucm081297.pdf (accessed May 21, 2018).

349 Grimmond T and Reiner S, 2012. Impact on Carbon Footprint: An LCA of Disposable vs

350 Reusable Sharps Containers in a Large US Hospital. Waste Man. Res. 30:639-642. DOI:

$351 \quad 10.1177 / 0734242 X 12450602$.

352 Grimmond T, Bylund S, Anglea C, at al., 2010. Sharps injury reduction using a sharps container

353 with enhanced engineering: A 28 hospital nonrandomized intervention and cohort study. Am. J.

354 Infect. Control, 38,799-805. doi:10.1016/j.ajic.2010.06.010.

355 Karlsson M and Ohman DP, 2005. Material consumption in the healthcare sector: Strategies to

356 reduce its impact on climate change - The case of Region Scania in South Sweden. J. Clean.

357 Prod. 13, 1071-1081. doi:10.1016/j.jclepro.2004.12.012.

358 NCASI, 2017. National Council for Air and Stream Improvement, Inc. (NCASI). 2017. 2014

359 Life Cycle Assessment of U.S. Average Corrugated Product - Prepared for the Corrugated

360 Product Alliance (CPA). Cary, N.C.: National Council for Air and Stream Improvement., Inc.

361 https://www.cccabox.org/wp-

362 content/uploads/2017/10/NCASI2014ExecutiveSummary_LCA_Final.pdf (accessed May 21, 363 2018). 
364 Nielsen AM, Li H and Zhang H. Compact detergents in China - A step towards more sustainable

365 laundry. A Life Cycle Assessment of four typical Chinese detergents. Household and Personal

366 Care Today 2013;8(5):30-5. https://www.novozymes.com/-

367 /media/Project/Novozymes/Website/website/document-library/LCAs/Compact-detergents-in-

368 China---A-step-towards-more-sustainable-laundry.pdf?la=en (accessed May 21, 2018).

369 NHS, 2016. Carbon update for the health and care sector in England 2015. Sustainable

370 Development Unit, National Health Service.

371 http://www.sduhealth.org.uk/documents/publications/2016/Carbon_Footprint_summary_HCS_u

372 pdate 2015 final.pdf (accessed Oct 14, 2018).

373 NHS, 2017. Identifying High Greenhouse Gas Intensity Procured Items for the NHS in England.

374 Sustainable Development Unit, National Health Service, Available at:

375 https://www.sduhealth.org.uk/documents/publications/2017/Identifying_High_Greenhouse_Gas

376 Intensity_Procured_Items for the NHS in_England_FINAL.pdf (accessed Oct 14, 2018).

377 PGH, 2013. Regulated Medical Waste (RMW) Minimization Strategies. Step 7. Review

378 Specialty RMW Streams: Sharps management, Practice Greenhealth, VA USA.

379 https://practicegreenhealth.org/topics/waste/waste-categories-types/regulated-medical-

380 waste/rmw-minimization-strategies (accessed May 21, 2018).

381 Shahmohammadi SS, Steinmann Z, Clavreul J, Hendrickx H, King H and Huijbregts M.

382 Quantifying drivers of variability in life cycle greenhouse gas emissions

383 of consumer products - a case study on laundry washing in Europe. International Journal of Life

384 Cycle Assessment 2017;Dec:1-10. https://link.springer.com/article/10.1007/s11367-017-1426-4

385 doi.org/10.1007/s11367-017-1426-4. (accessed May 21, 2018) 
386 Unger SR, Campion N, Bilec MM and Landis AE, 2016. Evaluating quantifiable metrics for

387 hospital green checklists. J. Clean. Prod. 127, 134-142.

388 http://dx.doi.org/10.1016/j.jclepro.2016.03.167.

389 USDOE, 2010. Energy-Consumption and Carbon-Emission Analysis of Vehicle and Component

390 Manufacturing. United States Department of Energy, Washington DC, USA.

391 https://greet.es.anl.gov/files/vehicle and components manufacturing (accessed May 21, 2018).

392 USDOT, 2001. 178.608. Vibration Standard. Pipeline and Hazardous Materials Safety

393 Administration, United States Department of Transportation, Washington DC, USA.

394 https://www.gpo.gov/fdsys/pkg/CFR-2011-title49-vol3/xml/CFR-2011-title49-vol3-sec178-

395 608.xml (accessed May 21, 2018)

396 USEP 2016. Greenhouse Gas Inventory Guidance: Direct Emissions from Mobile Combustion

397 Sources. United States Environmental Protection Agency, Jan 2018.

398 https://www.epa.gov/sites/production/files/2016-03/documents/mobileemissions_3_2016.pdf.

399 Accessed Oct 14, 2018.

400 USEPA eGRID, 2016. U.S. Environmental Protection Agency. Emissions \& Generation

401 Resource Integrated Database (eGRID), Feb 15, 2018. https://www.epa.gov/energy/emissions-

402 generation-resource-integrated-database-egrid (accessed May 14, 2018).

403 USEPA WARM, 2018. Management Practice Chapters, Documentation for Greenhouse Gas

404 Emission and Energy Factors Used in the Waste Reduction Model (WARM). United States

405 Environmental Protection Agency, Mar 2018. https://www.epa.gov/sites/production/files/2016-

406 03/documents/warm_v14_management_practices.pdf (accessed May 21, 2018).

407 WHO-HCWH (2009) World Health Organisation and Health Care Without Harm. Healthy 
408 Hospitals Healthy Planet Healthy People. Addressing climate change in health care settings.

409 http://www.who.int/globalchange/publications/healthcare_settings/en/index.html (accessed May

$41021,2018)$

411 WinPepi, 2016. Abraham J. WinPepi v11.65. Computer Programs for Epidemiologic Analysis.

412 http://www.brixtonhealth.com/pepi4windows.html (accessed May 21, 2018). 


\section{Table $\mathbf{1}$ (on next page)}

Annual sharps waste stream and GHG: comparison of disposable vs reusable sharps containers at LLUH. 


\begin{tabular}{|c|c|c|}
\hline & DSC & RSC \\
\hline Containers Manufactured & 48,460 & $3195^{\mathrm{a}}$ \\
\hline Containers landfilled annually & $35,925^{\mathrm{b}}$ & $0^{\mathrm{c}}$ \\
\hline Weight plastic landfilled (tonnes) & 31.8 & $0^{\mathrm{c}}$ \\
\hline Weight plastic incinerated (tonnes) & 18.8 & $0.4^{\mathrm{d}}$ \\
\hline Weight cardboard boxes (tonnes) & 8.2 & $0.1^{\mathrm{e}}$ \\
\hline Container exchanges & 48,460 & $33,356^{\mathrm{f}}$ \\
\hline MTCO2eq GWPg & 248.62 & 86.19 \\
\hline Adjusted Patient Days (APD) & 296,205 & 297,056 \\
\hline $\mathrm{MTCO}_{2}$ eq GWP per $10,000 \mathrm{APD}^{\mathrm{h}}$ & 8.37 & $2.90^{\mathrm{i}}(-65.3 \%)$ \\
\hline \multicolumn{3}{|c|}{ GHG, Greenhouse Gas; LLUH, Loma Linda University Health; $\mathrm{MTCO}_{2} \mathrm{eq}$, metric tonnes carbon } \\
\hline \multicolumn{3}{|l|}{ Global Warming Potential. } \\
\hline \multicolumn{3}{|c|}{ a 2,779.7 RSC manufactured in year one only, plus 3.7 replacement RSC annually (allowing for } \\
\hline \multicolumn{3}{|c|}{ reuse and recycling credits), plus 412 chemotherapy/pharmaceutical DSC annually. } \\
\hline \multicolumn{3}{|c|}{ b 8,245 Chemotherapy/Pharmaceutical DSC were incinerated/yr. } \\
\hline \multicolumn{3}{|c|}{${ }^{\mathrm{c}}$ No RSC were landfilled as all parts were either reused or recycled. } \\
\hline \multicolumn{3}{|c|}{ d Tonnes of chemo/pharma DSC incinerated (412 chemo DSC were used during RSC year) } \\
\hline
\end{tabular}


$11 \mathrm{~g}$ Emissions of GHG expressed in terms of global warming potentials, defined as the radiative

12 forcing impact of one mass-based unit $(\mathrm{kg})$ of a given GHG relative to an equivalent unit of

13 carbon dioxide over a given period of time (100 years) (British Standards Institute 2008).

$14 \mathrm{~h}$ 10,000 APD used as workload denominator to normalize base year comparison and facilitate inter-

15 hospital comparisons.

16 i $65.3 \%$ reduction; $\mathrm{P}<0.001 ;$ Rate Ratio $=2.90 ; \mathrm{CL}(95 \%)=2.27-3.71$.

17

18

19

20

21

22 
Figure 1

System boundary showing inputs, outputs, inclusions and exclusions

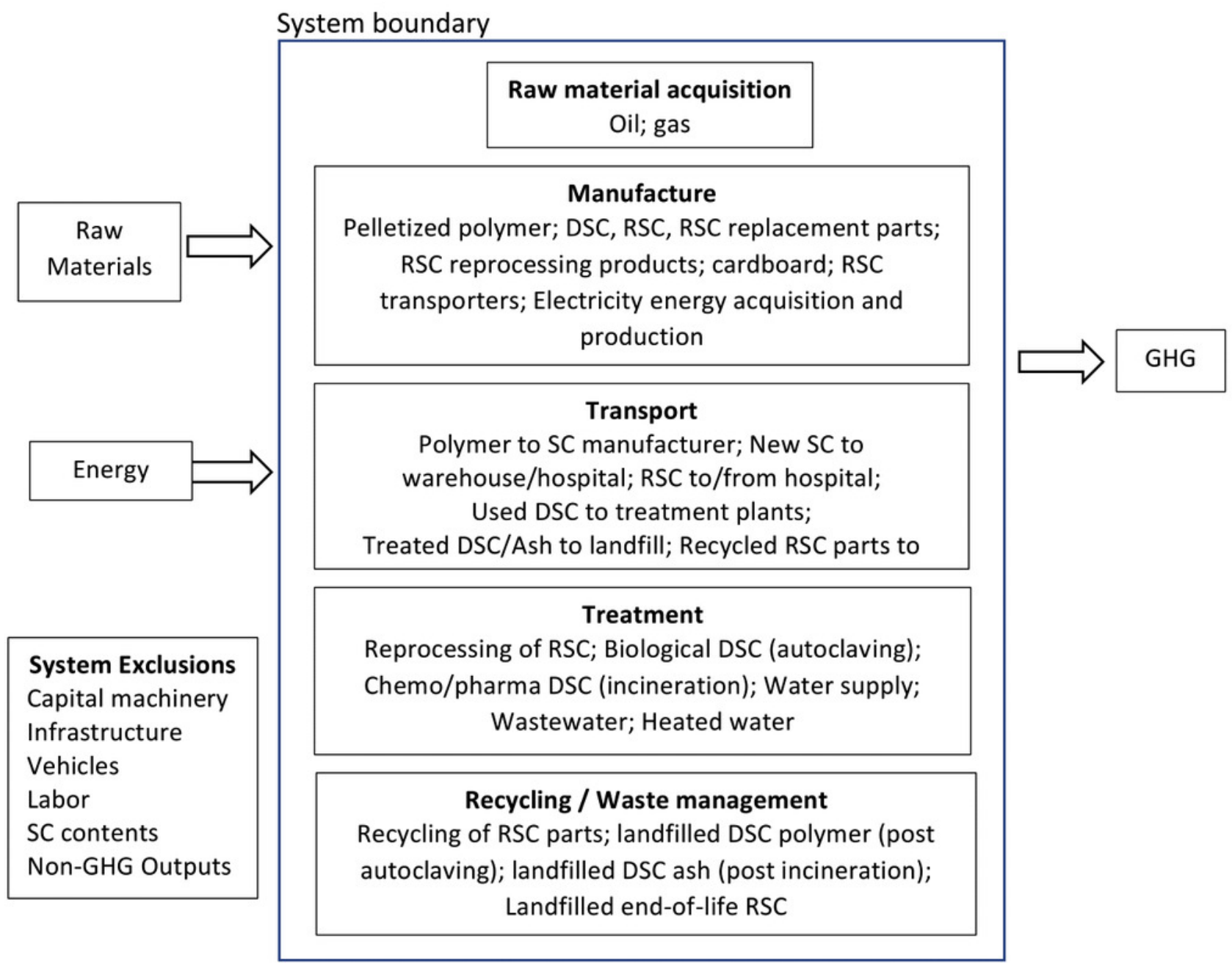




\section{Figure 2 (on next page)}

Annual greenhouse gas emissions by life stage of disposables and reusable sharps containers at Loma Linda University Hospital, with DSC normalised to Adjusted Patient Days. 


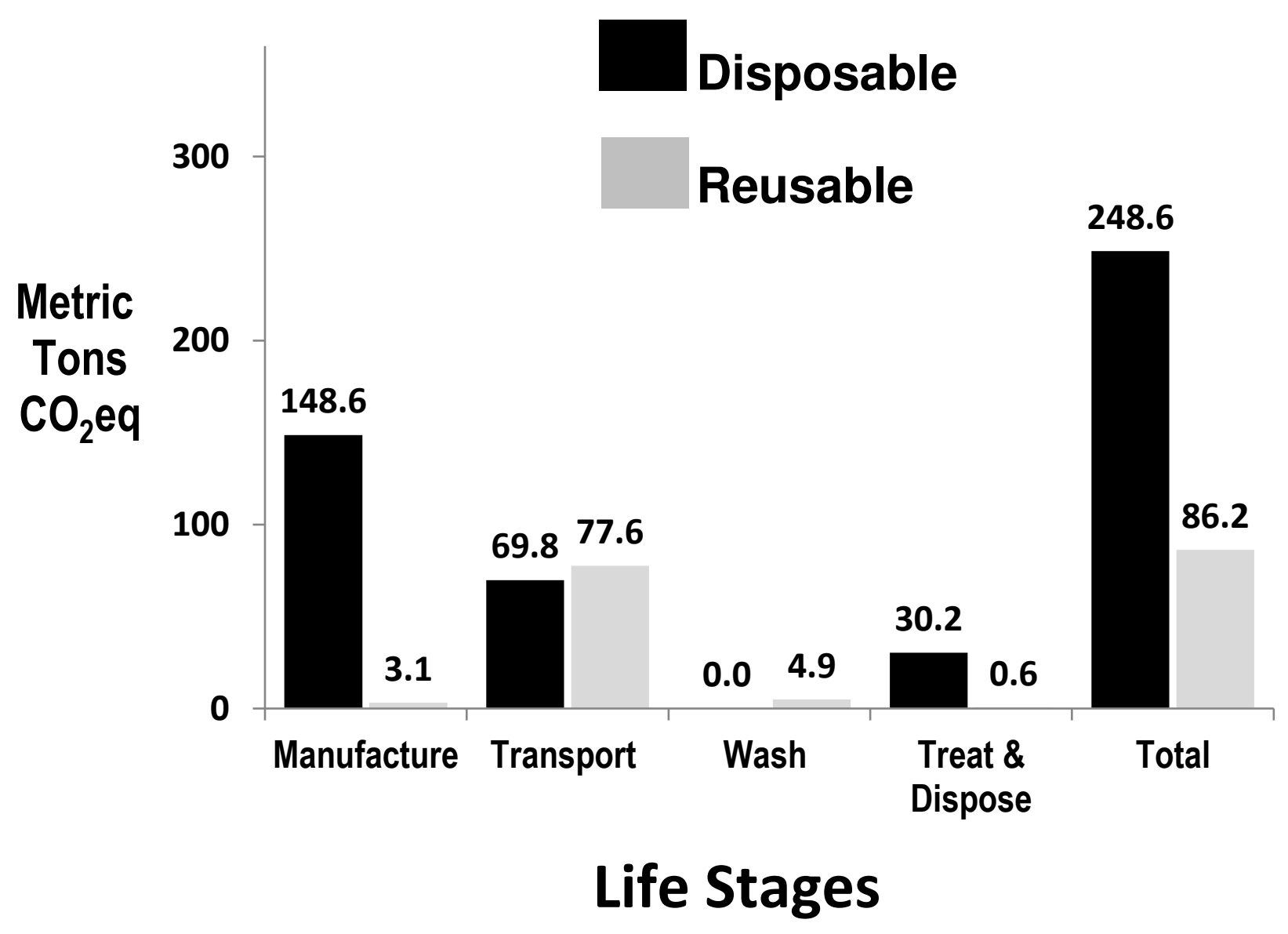

